\title{
Modeling, detecting and evaluating water ingress in aviation honeycomb panels
}

\author{
by V. P. Vavilov*, Y. Pan*, A. I. Moskovchenko* and A. Čapka** \\ * Tomsk Polytechnic University, Lenin Av., 30, Tomsk, Russia, vavilov@tpu.ru \\ **Tomas Bata University in Zlín, Vavrečkova 275, Zlín, Czech Republic, capka@ft.utb.cz
}

\begin{abstract}
A use of infrared thermography for quantitative evaluation of water hidden in honeycomb cells is discussed. Test case modeling has been performed by analyzing a 3D honeycomb panel model where water fully or partially occupies cells. Calculation of several test cases has allowed to better understand how the thickness of the water layer adjacent to an inspected skin, or the thickness of the air gap between skin and water, affects temperature anomalies and times of their appearance in active thermal tests. Experimental results have been obtained on both reference and real samples.
\end{abstract}

\section{Introduction}

Nondestructive testing (NDT) of water ingress in honeycomb panels of airplanes under exploitation remains an important aircraft maintenance problem. At a qualitative level, this problem is being solved at leading air companies by applying both passive and active modes of thermal NDT (TNDT). At Tomsk Polytechnic University, the research on detecting hidden water immediately after landing recently finished with the development of the corresponding federal guidelines (in collaboration with the State Institute of Civil Aviation). These guidelines have been used mainly in the inspection of Toupolvev-204 airplanes across the country. According to the approved normative document, quantitative water evaluation is to be done by applying the ultrasonic NDT method while infrared (IR) thermography is regarded as a screening inspection technique. Details of this earlier research can be found elsewhere $[1,2]$.

The current research is forwarded to understand whether solely IR thermography can be used for quantitative evaluation of water hidden in aviation honeycomb cells.

\section{Modeling cell water detection}

The modeling of plentiful test cases has been performed by analyzing a 3D honeycomb panel model where water can fully or partially occupy cells. In the latter case, water is distributed in a cell under the gravitational force being also present as the capillary water adjacent to cell walls. One-sided inspection can be made on both top and bottom panel surfaces while the water may contact a honeycomb skin ('bottom' test) or be separated from it by an air gap ('top' test).

Thermal properties of materials used in this study are presented in table 1 . We consider a simple honeycomb structure with square cells made of Nomex paper and the panel skin made of glass and carbon fiber reinforced plastic (GFRP and CFRP). In most cases, the skin thickness is $0.5 \mathrm{~mm}$ and the cell height $-10 \mathrm{~mm}$.

Table 1. Material thermal properties*

\begin{tabular}{|c|c|c|c|c|c|}
\hline Material & $\begin{array}{c}\text { Thermal } \\
\text { conductivity } K, \\
\mathrm{~W} /\left(\mathrm{m}^{\circ} \mathrm{C}\right)\end{array}$ & $\begin{array}{c}\text { Heat capacity, } \\
\mathrm{C}, \mathrm{J} /\left(\mathrm{kg}^{\circ} \mathrm{C}\right)\end{array}$ & $\begin{array}{c}\text { Density } \rho, \\
\mathrm{kg} / \mathrm{m}^{3}\end{array}$ & $\begin{array}{c}\text { Thermal } \\
\text { diffusivity } a, \\
\mathrm{~m}^{2} / \mathrm{s}\end{array}$ & $\begin{array}{c}\text { Effusivity e, } \\
\mathrm{W}^{1 / 2} /\left(\mathrm{m}^{2.0} \mathrm{C}\right)\end{array}$ \\
\hline $\begin{array}{c}\text { Carbon fiber } \\
\text { reinforced plastic } \\
\text { (CFRP) }\end{array}$ & 0.61 & 1758 & 1500 & $2.31 \cdot 10^{-1}$ & 1268 \\
\hline $\begin{array}{c}\text { Glass fiber } \\
\text { reinforced plastic } \\
\text { (GFRP) }\end{array}$ & 0.30 & 1775 & 1300 & $1.30 \cdot 10^{-1}$ & 832.0 \\
\hline Water & 0.59 & 4193 & 1000 & $1.41 \cdot 10^{-1}$ & 1573 \\
\hline Nomex paper & 0.14 & 1100 & 1000 & $1.27 \cdot 10^{-1}$ & 392,4 \\
\hline Epoxy adhesive & 0.18 & 1100 & 1200 & $1.36 \cdot 10^{-1}$ & 487.4 \\
\hline Air & 0.07 & 928.4 & 1.3 & $5.8 \cdot 10^{-5}$ & 9.192 \\
\hline
\end{tabular}




\subsection{D-to-1D geometry transition criterion}

The assumption of a 1D model means that the heat propagates only along a single in-depth coordinate $(z)$, therefore, the surface temperature $T$ is a function of $z$ and time $\tau$. One-layer 1D models are described with well-known 'classical' heat conduction solutions of which review in application to TNDT can be found in [3]. Two- and three-layer 1D models still can be solved analytically but the solutions become cumbersome because they require finding roots of sophisticated transcendent equations [4]. Finally, multi-layer 1D models can be effectively solved by using the semianalytical quadrupole technique [5].

The next class of thermal NDT models relates to the 2D cylindrical geometry where a disk-like defect is introduced into a disk-like sample (ThermoCalc-2D program from Innovation, Russia) [6].

Finally, the most flexible are $3 \mathrm{D}$ Cartesian models where one can simulate various thermal and optical phenomena accompanying the TNDT process. The ThermoCalc-3D software from Innovation allows modeling up to 36 anisotropic layers and up to 40 parallelepiped-like defects. The result of 3D modeling is a set of synthetic IR image sequences where the typical thermal NDT parameters (differential temperature signals $\Delta T$ and running contrasts $C=\Delta T / T$, where $T$ is the non-defect excess temperature) can be determined for areas of interest in regard to a reference ('dry') cell.

To define a 3D-to-1D geometry transition criterion in honeycomb structures with 'water' defects, we have simulated a square defect with the lateral size $h$ varying from $1 \times 1$ to $40 \times 40 \mathrm{~mm}$ by using the ThermoCalc-3D software (figure 1a). The results have been validated by using the Layer-3 Analytic program from Innovation which implements a 1D solution for a three-layer non-adiabatic plate (figure 1b) where the central layer represents either air (cell) or water, and the difference between two solutions yields $\Delta T$ values. In its turn, the accuracy of the analytical solution, where the roots of the corresponding transcendent equation are to be found numerically, was validated by comparing it with classical solutions in several extreme cases. The dependence $C_{m} v s . h$ presented in figure 1c for defect lateral size $h$ from $1 \times 1$ to $40 \times 40 \mathrm{~mm}$ reveals saturation for large defects (results are close for both CFRP and GFRP skins). In this particular case, the 3D-to-1D geometry transition criterion is $h \sim 5-10 \mathrm{~mm}$. In fact, the transition criterion depends on skin properties and cell height but, since we have analyzed a typical honeycomb structure (skin thickness from 0.5 to $1 \mathrm{~mm}$ ), the limit value of $h>10 \mathrm{~mm}$ can be considered as appropriate for 1D modeling. For example, the results in figure $1 \mathrm{a}, \mathrm{b}$ obtained in the case of the $40 \times 40 \mathrm{~mm}$ and laterally-infinite defects are very close (see the legend to the figure).

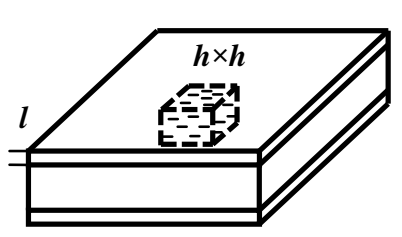

a)

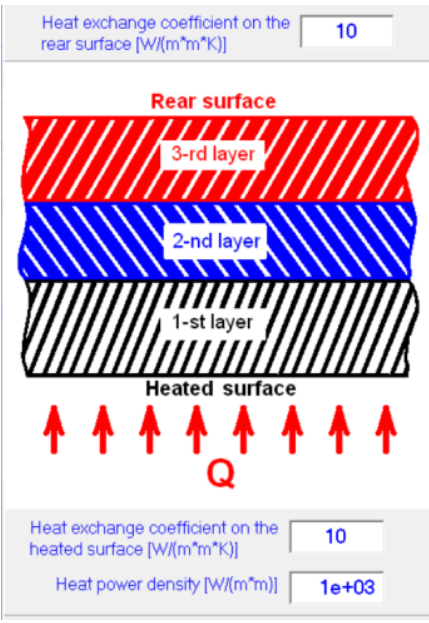

b)

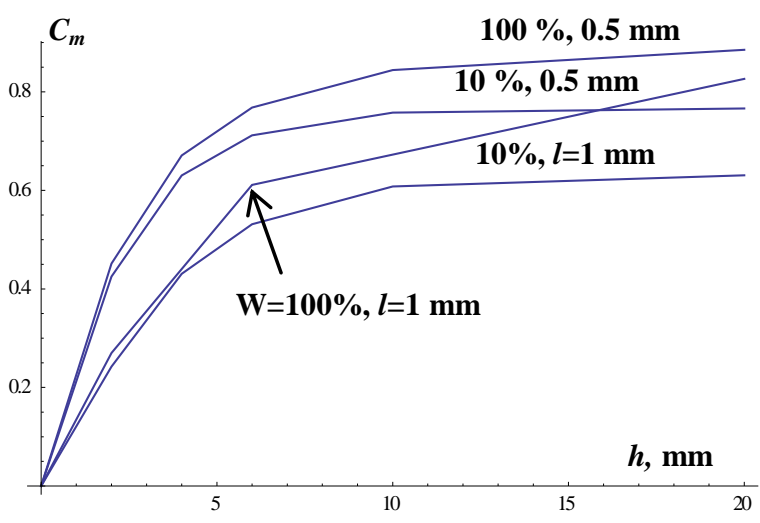

c)

Fig. 1. Transiting from $3 D$ to $1 D$ model:

a $-3 D$ model, defect $4 \times 4 \mathrm{~mm}: \Delta T=2.83^{\circ} \mathrm{C}, \tau_{m}=9 \mathrm{~s}$, defect $40 \times 40 \mathrm{~mm}: \Delta T=3.08^{\circ} \mathrm{C}, \tau_{m}=11 \mathrm{~s}$ (ThermoCalc-3D),

$b-1 D$ model, infinite lateral size, $\Delta T=3.14^{\circ} \mathrm{C}, \tau_{m}=10,6 \mathrm{~s}$ (Layer-3 Analytic),

$c-C_{m}$ vs. $h$ (GFRP skin, thickness 0.5 and $1 \mathrm{~mm}$ )

\subsection{D analysis of real test cases}

Some typical situations of water ingress detection are presented in figure 2 as particular ThermoCalc-3D models. Figure 2a shows two $10 \times 10 \mathrm{~mm}$ honeycomb cells filled with water and epoxy adhesive. In practice, these two substances should be distinguished because only the presence of water is regarded as a dangerous defect requiring an appropriate repair action. Since such actions may worsen panel rigidity, their number is limited for each particular component. Hidden water may occupy cells either fully (figure $2 a$ ) or in part (figure $2 b-c$ ). In the latter case, under the gravitation force, water contacts honeycomb skin on the bottom of a panel under test. If the inspection is fulfilled on this 
panel surface, the water detection conditions are the best (figure $2 b$ ), while the inspection on the top panel surface, i.e. through an air gap, may be more difficult if possible (figure 2c). We also introduce the so-called capillary water (figure $2 d)$ of which thickness can be very small.

The parameters of the model in this case were: $0.5 \mathrm{~mm}$-thick CFRP skin, Nomex paper-made cell height 10 $\mathrm{mm}$, heating power $10 \mathrm{~kW} / \mathrm{m}^{2}$, heating time $5 \mathrm{~s}$, process time $50 \mathrm{~s}$. The example of the evolutions of $\Delta T$ and $C$ in time are presented in figure 3 (100\% water content). The maximum values of these parameters and their observation times calculated for several test cases are given in table 1 . We remind that $\Delta T$ is linearly proportional to the absorbed power $Q$ that allows easy re-calculation of temperature values.

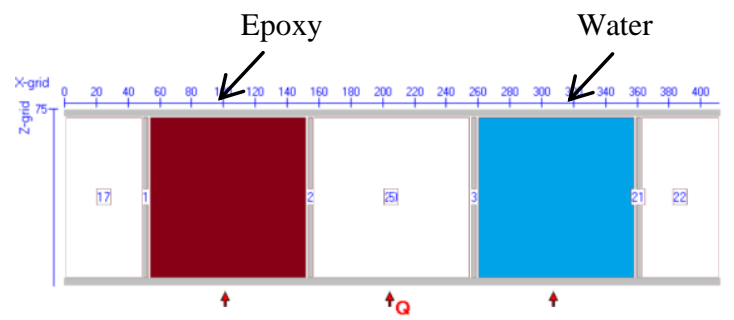

a)

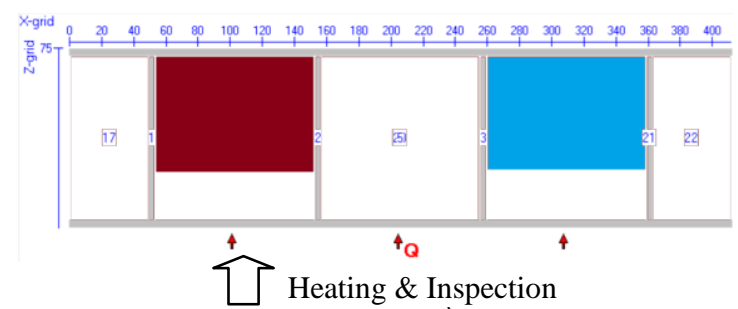

c)

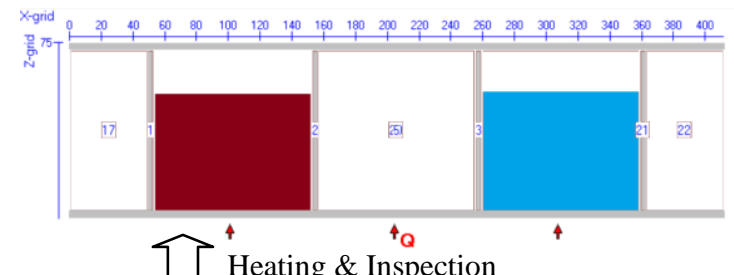

b)

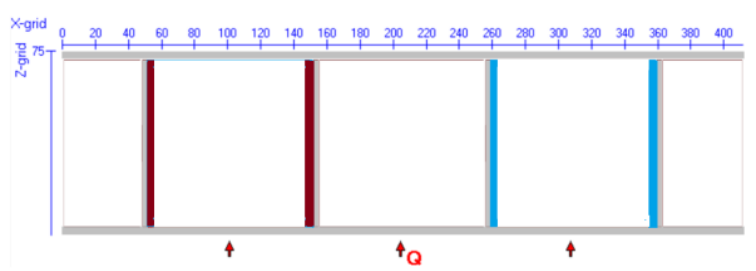

d)

Fig. 2. 3D numerical models (ThermoCalc-3D software):

a- $100 \%$ water/adhesive content,

$b$ - water down, heating from bottom ('bottom' test),

$c$ - water down, heating from top ('top' test),

d-capillary water

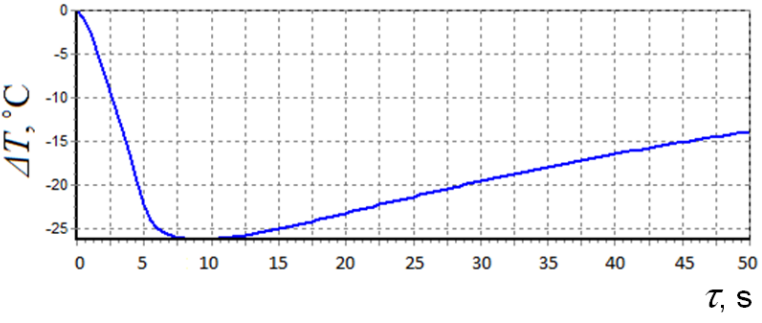

a)

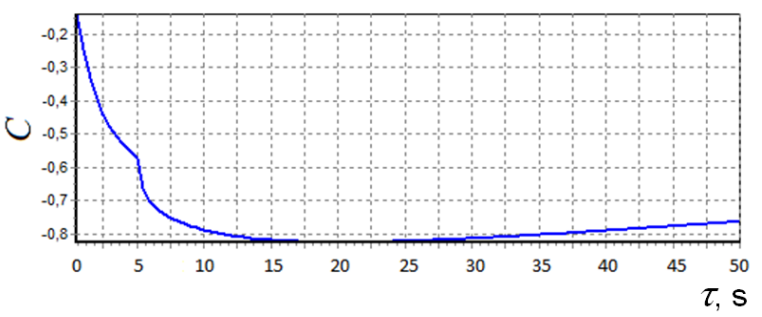

b)

Fig. 3. Evolution of temperature signal (a) and contrast (b) in time (100\% water content, one-sided test)

In principle, modeling results exhibit a 'classical' behavior of temperature signals over water-filled areas. Because of high heat capacity of water, defect areas keep colder that the background during the whole thermal process. Differential temperature signals reach maximums at particular times $\tau_{m}$, and $\Delta T$ extremums appear earlier than the extremums of $C$. As expected, all parameters essentially depend on the presence of air gap between the water and the inspected skin (see table 1). If the inspection is being done on the skin which is in contact with water, temperature signals are maximum being accompanied with shortest observation times. Moreover, in this case, water mass affects detection parameters only if water layer thickness is less than $4 \mathrm{~mm}$ (40\% of the cell volume). Respectively, one-sided thermal NDT being performed on the panel skin where cell water is separated from the skin by an air gap, results in low temperature signals and longer observation times.

It seems that quantitative evaluation of water content $V$ in honeycomb cells is a challenging task, and so far our results are not very optimistic. One idea of help which still needs further development is to perform inspection on both panel surfaces sequentially (this is possible on disassembled parts) and use a ratio of respective temperature signals $\Delta T_{1} / \Delta T_{2}$ or contrasts $C_{1} / C_{2}$, The examples of a calibration curve is presented in figure 4 to prove that the evaluation of water mass is possible, in particular, if water mass is under $50 \%$ by cell volume. 
Table 1. Optimum water detection parameters (CFRP honeycomb panel, modeling results)

\begin{tabular}{|c|c|c|c|c|}
\hline Test case & $\Delta T_{m},{ }^{\circ} \mathrm{C}$ & $\tau_{m}\left(\Delta T_{m}\right), \mathrm{s}$ & $C_{m}$ & $\tau_{m}\left(C_{m}\right), \mathrm{s}$ \\
\hline \multicolumn{5}{|c|}{ One-sided test procedure (skin contacts water) } \\
\hline $100 \%$ water content in cell * & -26.3 & 9 & -0.826 & 20 \\
\hline $75 \%$ & -26.3 & 9 & -0.826 & 20 \\
\hline $50 \%$ & -26.3 & 9 & -0.826 & 20 \\
\hline $40 \%$ & -26.3 & 9 & -0.826 & 20 \\
\hline $30 \%$ & -26.3 & 9 & -0.822 & 18.5 \\
\hline $20 \%$ & -26.1 & 9 & -0.803 & 15 \\
\hline $10 \%$ & -24.7 & 7.5 & -0.721 & 10 \\
\hline \multicolumn{5}{|c|}{ One-sided test procedure (skin contacts air) } \\
\hline $75 \%$ water content in cell & -6.504 & 40 & -0.421 & 117 \\
\hline $50 \%$ & -2.443 & 65 & -0.3070 & 161.5 \\
\hline $40 \%$ & -1.822 & 67 & -0.1858 & 170 \\
\hline $30 \%$ & -1.268 & 73 & -0.1381 & 172 \\
\hline $20 \%$ & -0.838 & 81 & -0.0936 & 168 \\
\hline $10 \%$ & -0.463 & 84 & -0.0491 & 153 \\
\hline
\end{tabular}

* If water fully fills a cell, inspection results are identical on both panel surfaces

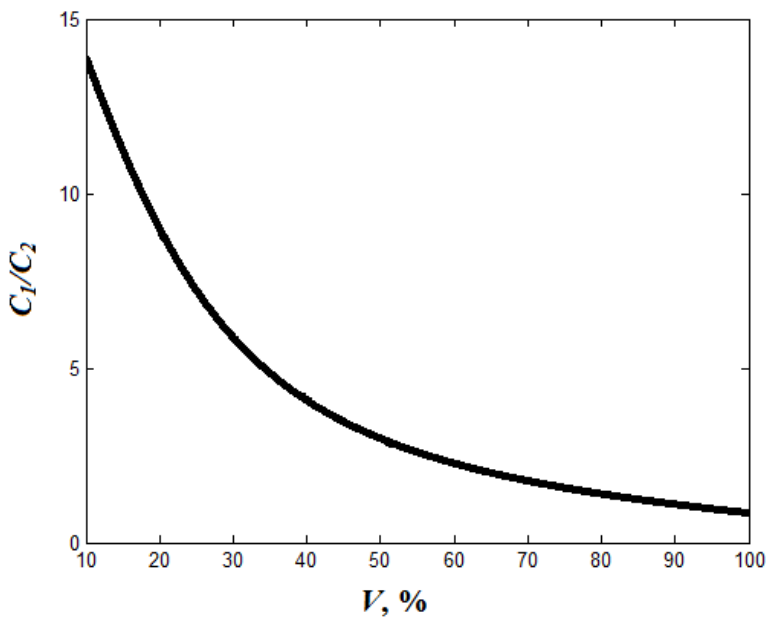

a)

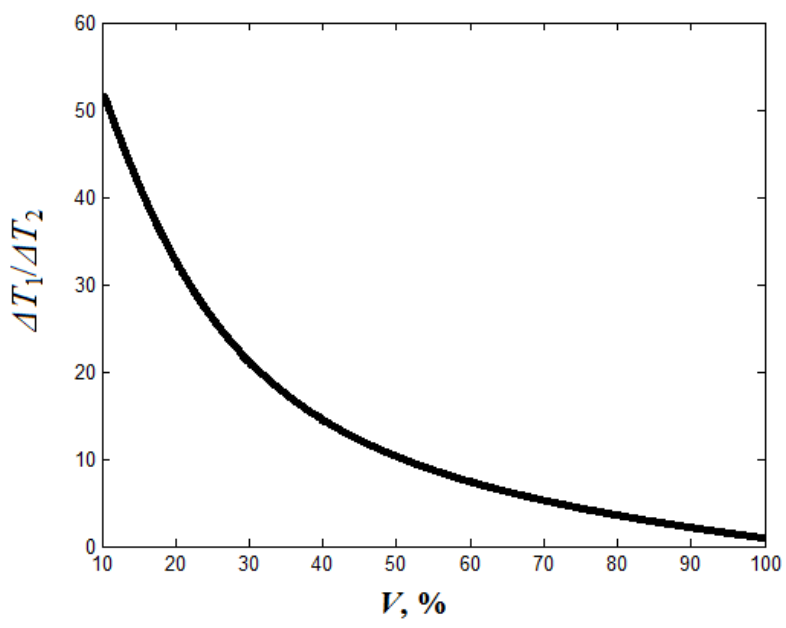

b)

Fig. 4. Temperature signal (a) and contrast (b) ratio vs. water content if a one-sided test procedure is sequentially applied to both panel surfaces

\subsection{Distinguishing between water and adhesive}

It has been shown elsewhere that, in a one-sided TNDT test, an additional useful information about material defects can be obtained by producing material effusivity maps [7]. The details of this approach in application to water detection are described in a coming paper. We will limit ourselves with the statement that, since water effusivity is much higher than that of air, the corresponding sections of effusivity vs. time profiles start to behave in a different way after a particular observation time which is determined by skin thickness. This is illustrated in figure 5 with both theoretical and experimental data where the inflection point is clearly seen at the $\tau_{\text {inf }}$ time. Note that, in the experiment, the so-called apparent effusivity has been determined.

\section{Experimental illustrations}

The first experimental session was performed in order to evaluate an optimum technique of thermal stimulation. A $10 \mathrm{~mm}$-thick aviation GFRP honeycomb panel area included 8 adjacent cells fully filled with water. Four other cells contained about $20 \%$ of water. Stimulation was fulfilled by using: 1) two light emitting diodes (LEDs) panels, $1 \mathrm{~kW}$ in total, 2) two halogen lamps, $2 \mathrm{~kW}$ in total, 3) air blower, $2 \mathrm{~kW}$. Heating duration was $5 \mathrm{~s}$, and temperature recording was performed by using a NEC Avio TH-9100 IR imager (image format $320 \times 240$, temperature resolution 60 mK, acquisition 
frequency $1 \mathrm{~Hz}$ ). The recorded image sequences were processed by means of the ThermoFit Pro software from Innovation. Figure 6 shows the IR thermograms of the sample at $2 \mathrm{~s}$ after heating stopped.

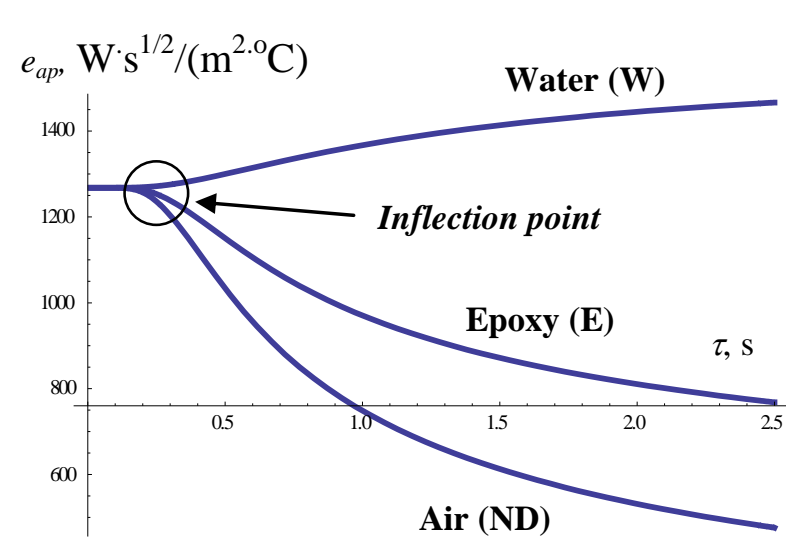

a)

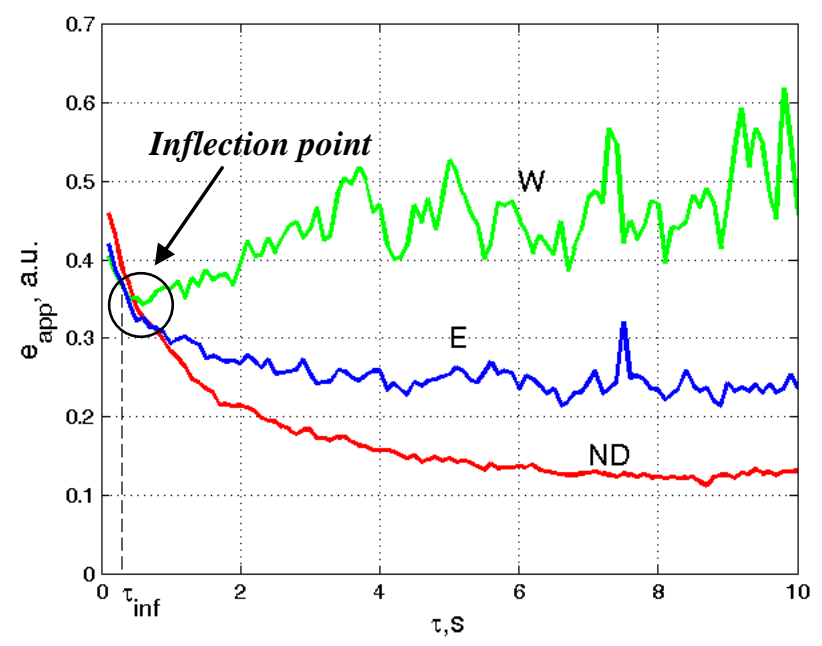

b)

Fig. 5. Effusivity of a GFRP honeycomb structure (cell height $10 \mathrm{~mm}$ ) vs. time: a - theory (skin thickness $0.5 \mathrm{~mm}$ ), $b$ - experiment (skin thickness $0.8 \mathrm{~mm}$ )

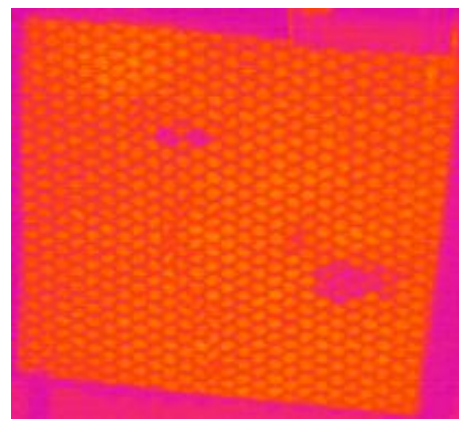

a)

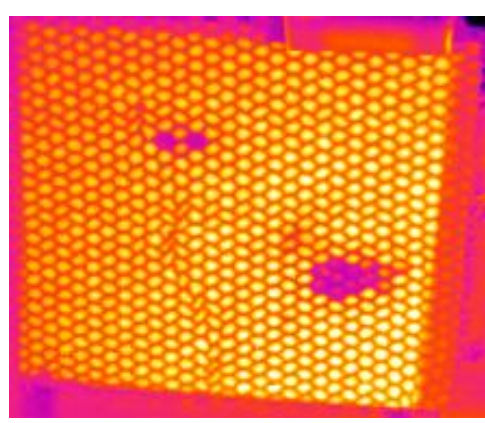

b)

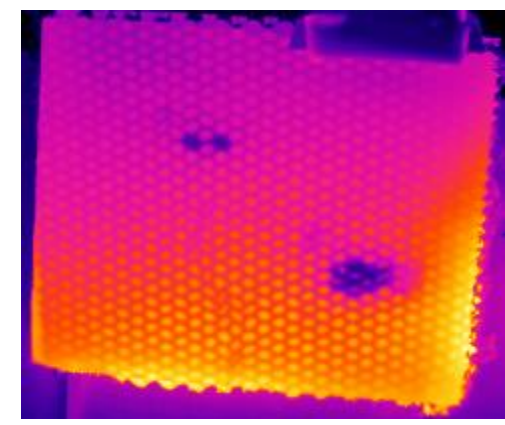

c)

Fig. 6. IR thermograms of a $10 \mathrm{~mm}$-thick GFRP honeycomb panel under three types of thermal stimulation: - LEDs, $b$ - halogen lamps, $c$ - air blower

The best results were obtained by using halogen lamps while the LEDs heater provided lower signals because of lower absorbed power, and the heating with hot air was uneven. All cells fully filled with water can be easily detected. Among four partially-filled cells, only two can be identified as defective, and their weak contrast is explained by the presence of the air gaps. Note that, in all images, honeycomb cells made of aluminum, are clearly seen because of heat sink into aluminum.

In the next experiment, the same sample was frozen at the temperature $-2{ }^{\circ} \mathrm{C}$ for 20 hours in order to simulate TNDT during airplane landing. Both passive and active (10 s heating with halogen lamps) thermal tests were applied to result in the IR thermograms shown in figure 7.

In the passive regime, only the cells with $100 \%$ of water were detected. The additional heating of the sample ensured images of a high quality, where all water-filled cells were reliably identified along with few cells probably filled with adhesive.

All test cases above have been quantitatively compared by using a signal-to-noise ratio (SNR) approach [8]. The results are presented in table 2. 


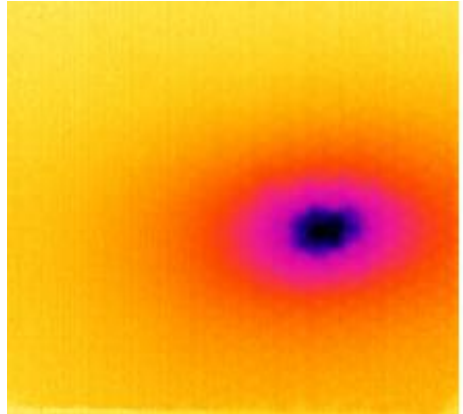

a)

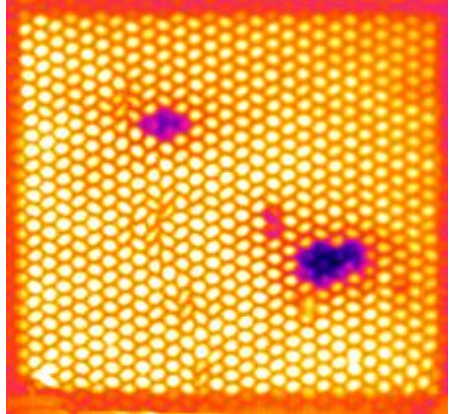

b)

Fig. 7. IR thermograms of a $10 \mathrm{~mm}$-thick GFRP honeycomb panel after freezing: a - passive test, $b$ - active test

Table 2. Comparing several types of thermal stimulation in the inspection of a $10 \mathrm{~mm}$-thick GFRP honeycomb panel

\begin{tabular}{|l|c|c|c|}
\hline \multicolumn{1}{|c|}{ Test case } & $S N R_{\max }$ & $\Delta T_{\max }$ & $C_{\max }$ \\
\hline LEDs heating & 5.1 & $-1.17^{\circ} \mathrm{C}$ & -0.0387 \\
\hline Halogen lamp heating & 26.1 & $-6.37^{\circ} \mathrm{C}$ & -0.169 \\
\hline Hot air heating & 24.2 & $-13.38^{\circ} \mathrm{C}$ & -0.335 \\
\hline Passive test after freezing & 90.7 & $-12.1^{\circ} \mathrm{C}$ & -0.483 \\
\hline Active test after freezing & 56.8 & $-13.95^{\circ} \mathrm{C}$ & -1.09 \\
\hline
\end{tabular}

The influence of water content on surface temperature signals was studied on a honeycomb surrogate made of GFRP (cell size $20 \times 20 \times 25 \mathrm{~mm}$, GFRP cell wall thickness $0.5 \mathrm{~mm}$ ) and heated with two halogen lamps (500 W each) for 3-5 s. IR thermogram acquisition rate was $10 \mathrm{~Hz}$ in this case.

Figure $8 \mathrm{a}$ shows the sample in the vertical position after $10 \mathrm{~s}$ heating. The cells filled with water by 50 and $100 \%$ are clearly identified (see two bottom indications) while the cell with $10 \%$ water content (left top) is not detected. Since cells are big and vertically-positioned, water location is well seen in the cell with $50 \%$ of water (bottom left).

In the horizontal position, if the test is done on the bottom sample surface where the water is in contact with the skin, all three cells filled with water are characterized by abnormal temperature in regard to the 'dry' cell (top right), see figure $8 \mathrm{~b}$. As expected, when the test is done on the top panel surface, temperature signals turn to be much lower because of air gaps; for example, the cell with $10 \%$ of water is not distinguishable from the 'dry' one (figure 8c).

$10 \%$

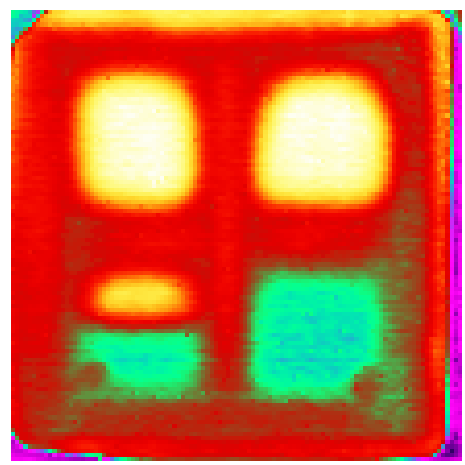

$50 \%$

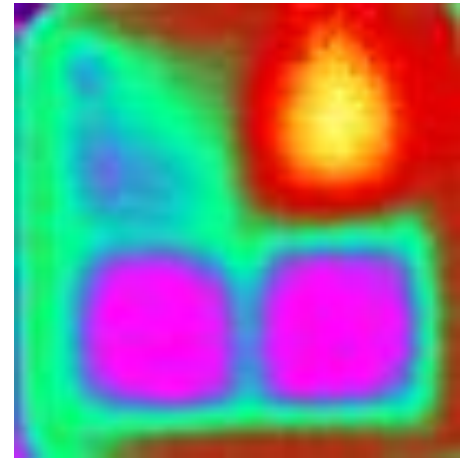

b)

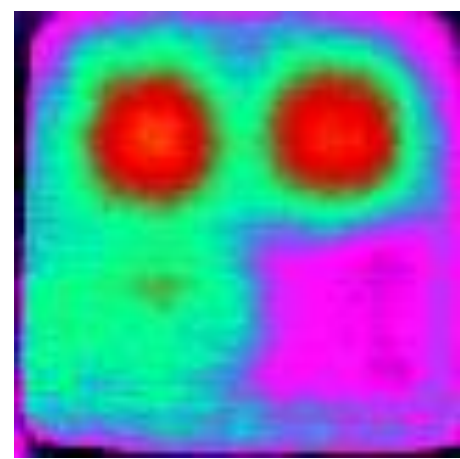

c)

Fig. 8. IR thermograms of a honeycomb surrogate (cell size $20 \times 20 \times 25 \mathrm{~mm}$, cell wall thickness $0.5 \mathrm{~mm}$ ):

$$
\begin{aligned}
& \text { a-vertical position, } 10 \text { s heating, } \\
& b-\text { horizontal position, inspecting bottom panel surface, } 10 \text { s heating, } \\
& c-\text { horizontal position, inspecting bottom panel surface, } 20 \text { s heating }
\end{aligned}
$$

The evolutions of $\Delta T$ on both sample surfaces are shown in figure 9. In the optimal test case ('bottom' test), the maximum $\Delta T$ signals are: $-12.7{ }^{\circ} \mathrm{C}(10 \%$ water $),-14.07{ }^{\circ} \mathrm{C}(50 \%)$ and $-14.21{ }^{\circ} \mathrm{C}(100 \%)$. The optimum observation times are: 13, 14 and $14 \mathrm{~s}$. When inspecting the top panel surface, the corresponding parameters are: $\Delta T=-$ $0.29{ }^{\circ} \mathrm{C}$ and $28 \mathrm{~s}(10 \%$ water $),-3.16{ }^{\circ} \mathrm{C}$ and $27 \mathrm{~s}(50 \%),-8.95{ }^{\circ} \mathrm{C}$ and $17 \mathrm{~s}(100 \%)$. In general, the behavior of 
temperature signals both qualitatively and quantitatively is in accordance with the theory, and a certain discrepancy can be explained by some uncontrollable test parameters.

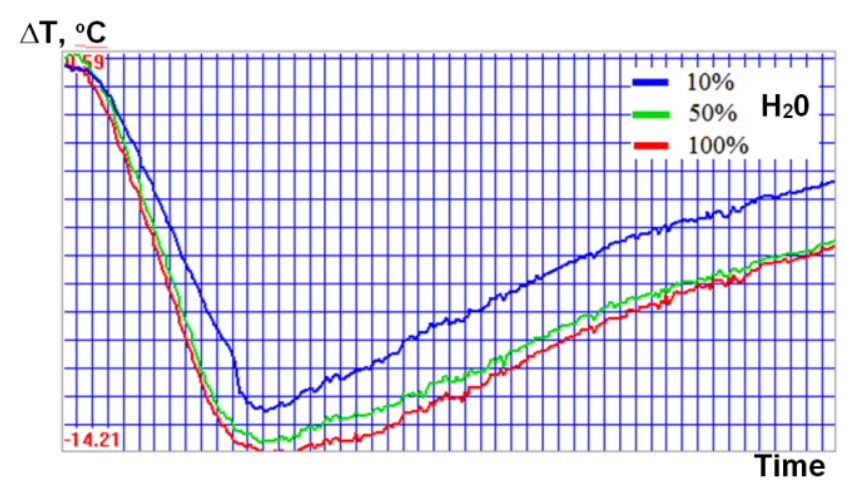

a)

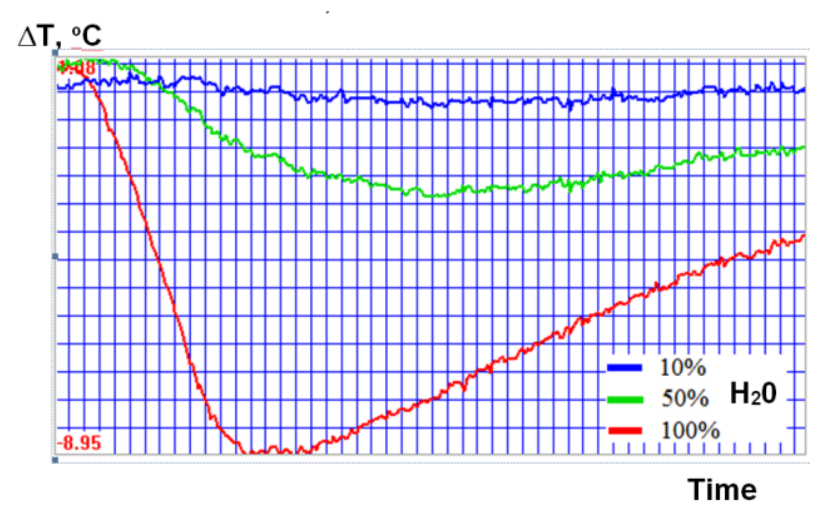

b)

Fig. 9. $\Delta T$ vs. $\tau$ : a-one-sided test, bottom panel surface, $b$ - one-sided test, top panel surface

The ratios of temperature signals on both surfaces $\Delta T_{1} / \Delta T_{2}$ that was suggested above for water mass evaluation are: $43.8,4.5$ and 1.6 respectively for 10,50 and $100 \%$ water content being comparable with the values predicted by figure $4 a$.

\section{Conclusions}

- The most important dependencies between sample parameters and temperature signals in honeycomb water detection can be found by using a simple 1D model of heat conduction in a three-layer plate, but some more subtle phenomena still require 3D numerical modeling.

- It seems that quantitative evaluation of water content in honeycomb cells by using solely IR thermography is a challenging task, and the obtained results are not yet very optimistic. One suggestion is to perform inspection on both panel surfaces (this is possible on disassembled parts) and use a ratio of respective temperature signals $\Delta T_{1} / \Delta T_{2}$ or contrasts $C_{1} / C_{2}$ as a calibration function.

- Since water effusivity is much higher than that of air, the corresponding sections of effusivity vs. time profiles start to behave in a different way after a particular observation time (inflection point) which is determined by skin thickness. This allows reliable discrimination between water and adhesive in cells.

- Halogen lamps still remain a convenient tool for thermal stimulation of honeycomb structures. The highest values of signal-to-noise ratio appear if cell water is frozen before a test.

\section{REFERENCES}

[1] Vavilov V., Klimov A. and. Nesteruk D., "Detecting water in aviation honeycomb structures by using transient IR thermographic NDT", Proc SPIE "Thermosense-XXV", Vol. 5073, p. 345-354, 2003.

[2] Vavilov V.P. and Nesteruk D.A., "Detecting water in aviation honeycomb structures: the quantitative approach", J. Quant. Infra Red Thermography, Vol. 1, No. 2, p. 173-184, 2004.

[3] Marinetti S. and Vavilov V., "Sensitivity analysis of classical heat conduction solutions applied to materials characterization”, Int. J. of Heat Transf. Eng., Vol. 26, No. 9, p. 50-60, 2005.

[4] Vavilov V.P., "Modeling thermal NDT problems", International Journal of Heat and Mass Transfer, Vol. 72, p. 7686, May 2014.

[5] Maillet D., Andre S., Batsale J-C. and Degiovanni A., "Thermal quadrupoles: solving the heat equation through integral transforms", John Wiley \& Sons Publisher, England, 2000, $360 \mathrm{p}$.

[6] Vavilov V.P., Burleigh D.D. and Demin V.G., "Advanced modeling of thermal NDT problems: from buried landmines to defects in composites", Proc. SPIE "Thermosense-XXIV", Vol. 4710, pp. 507-521, 2000.

[7] Balageas D.L., Krapez J.-C. and Cielo P., "Pulsed photo-thermal modeling of layered materials", J. Appl. Physics, Vol. 59, No. 2, p. 348-357, 1986.

[8] Vavilov V.P. and Burleigh D.D., "Review of pulsed thermal NDT: Physical principles, theory and data processing", NDT \& E International, Vol. 73, p. 28-52, 2015. 